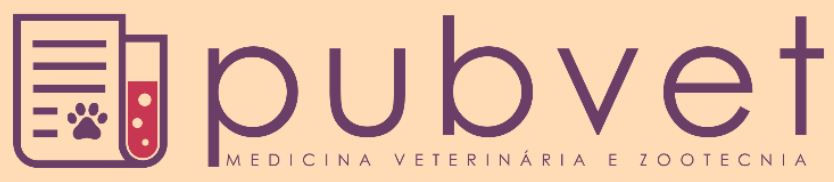

https://doi.org/10.31533/pubvet.v15n04a782.1-11

\title{
Eutanásia: Morte humanitária
}

\section{Thamires Fernandes Figueiredo González ${ }^{1}$, Thereza Christina de Vasconcelos ${ }^{2} \Phi$, Isabele Barbieri dos Santos ${ }^{3 *} \theta$}

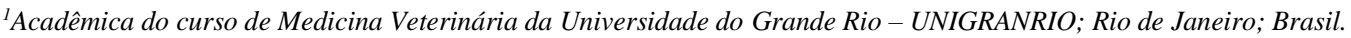

${ }^{2}$ Docente do curso de Medicina Veterinária da Universidade do Grande Rio - UNIGRANRIO; Rio de Janeiro; Brasil.

${ }^{3}$ Médica Veterinária, Doutora em Ciências, Tecnologista em Saúde Pública do Cento de Experimentação Animal do Instituto Oswaldo Cruz da Fundação Oswaldo Cruz - Fiocruz; Rio de Janeiro; Brasil.

*Autor por correspondência, E-mail: isabele.santos@ioc.fiocruz.br

Resumo. Na medicina veterinária a eutanásia é uma prática muito comum, que visa interromper o sofrimento do animal, em decorrência de alguma patologia que não tenha cura ou de processos dolorosos. A palavra eutanásia de acordo com o dicionário significa uma morte sem dor ou sofrimento. O médico veterinário tem competência de conseguir avaliar e decidir em que momento a eutanásia deve ser realizada, ele deve saber quais métodos são permitidos e proibidos para realizar este procedimento de acordo com a legislação brasileira. Por ser um procedimento ainda muito polêmico ao entendimento de muitas pessoas, os médicos veterinários acabam não recebendo todo reconhecimento que merecem, muitas vezes por falta de informação, afinal esta é uma das situações mais delicadas que se encontra nesta profissão. Este trabalho tem como objetivo reunir e expor o máximo de informação sobre a eutanásia existente na literatura, enfatizar que este procedimento é pautado na legislação, e conseguir esclarecer que é um procedimento que se faz necessário ser mais debatido durante a vida acadêmica, por que na vida profissional o médico veterinário deve estar preparado para decidir quando vai realizar e a lidar com fatores externos, como por exemplo, impactos psicológicos.

Palavras-chaves: Dor, sofrimento, eutanásia, medicina veterinária

\section{Euthanasia: Death Humanitarian}

Abstract. In veterinary medicine euthanasia is a very common practice, where it aims to interrupt the animal's suffering, due to some pathology that has no cure or painful processes. The word euthanasia according to the dictionary means a death without pain or suffering. Based on the position of being able to carry out this process and also having the competence to be able to evaluate and decide when euthanasia should be carried out, the veterinarian must know what methods and procedures are allowed and prohibited before carrying out this process. As it is still a very controversial procedure for many people to understand, veterinarians end up not receiving all the recognition they deserve, and often for lack of information, after all this is one of the most delicate situations found in this profession. This work aims to gather and expose the maximum amont of information about euthanasia in the literature, and to emphasize that this procedure is bases on legislation, and to be able to clarify that it is a procedure that is necessary to be more debated during academic life, why in professional life the veterinarian life must be prepared to decide when to perform and deal with external factors, such as psychological impacts.

Keywords: Pain, suffering, euthanasia, veterinary medicine 


\section{Eutanasia: muerte humanitária}

Resumen. En medicina veterinaria, la eutanasia es una práctica muy común, cuyo objetivo es interrumpir el sufrimiento del animal, debido a alguna patología que no tiene cura o de procesos dolorosos. La palabra eutanasia según el diccionario significa una muerte sin dolor ni sufrimiento. Según la posición de poder llevar a cabo este proceso y también tener la competencia para poder evaluar y decidir cuándo se debe llevar a cabo la eutanasia, el veterinario debe saber qué métodos y procedimientos están permitidos y prohibidos antes de llevar a cabo este proceso. Como aún es un procedimiento muy controvertido para la comprensión de muchas personas, los veterinarios terminan sin recibir todo el reconocimiento que merecen, y a menudo por falta de información, después de todo, esta es una de las situaciones más delicadas que se encuentran em esta profesión. Este trabajo tiene como objetivo recopilar y exponer información sobre la eutanasia en la literatura, y enfatizar que este procedimiento queda guiado por la legislación, y poder aclarar que es un procedimiento que es necesario debatir más durante la vida académica, por qué en la vida profesional, el veterinario debe estar preparado para decidir cuándo actuar y tratar con factores externos, como los impactos psicológicos.

Palabras clave: Dolor, sufrimiento, eutanasia, medicina veterinaria

\section{Introdução}

Spinosa \& Spinosa (2006) descreveram o termo eutanásia, como: significa eû (do grego bem, bom) + thánatos (do grego morte); estes termos se referem a uma morte sem sofrimento, sendo utilizada para pôr fim no sofrimento de um animal com uma patologia sem cura. De acordo com Marchitelli \& Shearer (2020), a eutanásia também visa diminuir, minimizar ou eliminar o distresse e a dor. Já a Resolução Normativa n 37, de 15 de fevereiro de 2018, do Conselho Nacional de Controle de Experimentação Animal (CONCEA, 2018), define eutanásia como a prática de causar a morte de um animal de maneira controlada e assistida para alívio da dor e/ou do sofrimento.

O Código de Ética do Médico Veterinário (CFMV, 2016) diz que o médico veterinário exercendo sua profissão, deve sempre usar métodos humanitários a fim de que seja necessário acabar com a dor e o sofrimento dos animais. Se faz importante que o método escolhido deve ser comprovadamente aceitável e cientificamente comprovado, e atender todos os aspectos éticos estabelecidos na Resolução 1.000 de 11 de maio de 2012, pelo Conselho Federal de Medicina Veterinária (CFMV, 2012).

Botoni et al. (2012) concluíram que a eutanásia sempre deve ser realizada a favor dos animais, o Médico Veterinário deve avaliar caso ainda tenha perspectiva de vida, para que este procedimento não ocorra sem que haja um embasamento necessário. E caso já não haja mais nenhuma terapêutica ou recurso que se possa fazer a manutenção da vida deste animal, a eutanásia é indicada.

Este trabalho tem como objetivo reunir e expor o máximo de informação sobre a eutanásia existente na literatura, enfatizar que este procedimento é pautado na legislação, e esclarecer que é um procedimento que se faz necessário ser mais debatido durante a vida acadêmica, por que na vida profissional o médico veterinário deve estar preparado para decidir quando vai realizar e a lidar com fatores externo, como por exemplo, impactos psicológicos.

\section{Eutanásia e suas condições}

A eutanásia visa causar a morte do animal de maneira controlada e assistida para aliviar dor e/ou sofrimento, então ela se faz necessária em muitos momentos. De acordo com o Guia Brasileiro de Boas Práticas para a Eutanásia em Animais (CFMV, 2012), a eutanásia vai ser indicada quando o animal estiver comprometido, principalmente seu bem-estar, de forma que não exista maneiras de conseguir diminuir ou extinguir sua dor, por meio de sedativos, analgésicos ou outros tratamentos. É indicado também caso o animal seja uma ameaça à saúde pública, uma ameaça ao meio ambiente ou também à fauna nativa; em animais que são usados para fins de pesquisa e experimento para pesquisas; e em casos que o proprietário não tenha condição financeira para bancar o tratamento do animal. Deixando claro que estas medidas acima citadas só serão utilizadas e aceitas caso não exista em hipótese alguma uma 
medida alternativa que possa salvar ou eliminar a dor do animal. Deve-se também estar atento ao bemestar desses animais durante a realização deste procedimento, que deve ser realizado de forma ética e técnica pelo médico veterinário. Os animais não devem assistir a eutanásia de outros animais porque isto pode gerar medo e ansiedade. O ambiente de realização da eutanásia deve ser livre de odor e secreção de outros animais, e a contenção deve ser a mais cuidadosa possível (Manica, 2018).

Durante o procedimento de eutanásia, devem ser seguidos os princípios do bem-estar animal como: garantir que se tenha respeito aos animais; que consiga reduzir ou eliminar todo desconforto e dor; garantir a perda da consciência após a sedação; o procedimento deve ser realizado de acordo com a espécies, idade e o estado fisiológico do animal e deve diminuir ao máximo o medo e a ansiedade, de forma segura e irreversível. Se faz necessário que os médicos veterinários tenham treinamento e ajam de forma humanitária, a ponto que eles consigam reconhecer sofrimento, qual grau de consciência e confirmar a morte do animal, além de assegurar que ocorra pouco ou nenhum impacto ambiental. É papel do médico veterinário fazer com que se tenha pouco ou nenhum risco para quem está presente no momento da eutanásia, e conseguir reduzir o impacto emocional negativo que este procedimento possa vir a acarretar a quem se faz presente naquele momento (CFMV, 2012).

De acordo com Oliveira et al. (2003), para que se assegure o bem-estar dos animais, todos critérios têm que ser fundamentados e utilizados métodos indolores, causando perda rápida de consciência e levando á morte, aonde se tenha o mínimo de contenção para que reduza a excitação do animal. É importante também levar em consideração a espécie, idade e o estado de saúde e físico do animal.

\section{Tipos de eutanásia}

De acordo com Massone (2019), existem várias modalidades para realizar a eutanásia, porém os métodos recomendados são aqueles realizados de forma humanitária e que não causem desconforto, dor ou asfixia durante o ato, então são considerados como métodos aceitáveis aqueles que causam a parada cardíaca e respiratória, simultaneamente.

Conforme Marchitelli \& Shearer (2020), existem 3 mecanismos básicos de eutanásia: depressão direta dos neurônios que possuem função vital, hipóxia e ruptura física da atividade no cérebro.

Os métodos de eutanásia são classificados como métodos aceitáveis, métodos aceitáveis sob restrição e métodos inaceitáveis. Os métodos aceitáveis são aqueles que, cientificamente, findam em uma morte humanitária, uma vez que sejam usados como métodos exclusivos de eutanásia. Já os métodos aceitos sob restrição são aqueles que, por particularidades próprias, não fornecem uma morte humanitária, por exemplo, quando se tem problemas que podem prejudicar a segurança de quem está executando. Sendo importante frisar que este só é usado quando não se tem nenhuma possibilidade de usar um método aceitável. Pode associar um método aceitável com um método aceitável sob restrição, a fim de que se associe duas técnicas para que se consiga obter uma morte mais humanitária. E por fim os métodos inaceitáveis que são aqueles considerados desumanos e são proibidos de serem utilizados, e quando utilizados são considerados uma infração gravíssima à ética. Estes métodos causam dor, sofrimento e muita angústia aos animais. Como exemplo, podemos citar: embolia gasosa, imersão em formol, hidrato de cloral, afogamento, entre outros (CONCEA, 2018; Marchitelli \& Shearer, 2020).

Os métodos aceitáveis são subdivididos em: métodos químicos e métodos físicos (CONCEA, 2018; Marchitelli \& Shearer, 2020).

\section{Métodos químicos de eutanásia}

São os mais aceitáveis, onde se engloba o uso de medicamentos anestésicos injetáveis, que são utilizados para realizar procedimentos mais seguros e de forma mais humanitária que existe. É importante salientar que sempre se deve estar atento à forma que o produto deve ser usado, via de administração, dose administrada e se faz necessário a associação com outros medicamentos. Entre os métodos químicos utilizados, serão citados os mais importantes na rotina clínica (Marchitelli \& Shearer, 2020). 


\section{Barbitúricos}

De acordo com o Guia de Boas Práticas para Eutanásia em Animais (CFMV, 2012; CONCEA, 2018), são as substâncias mais utilizadas na rotina clínica, e para a maioria das espécies animais. Quando utilizado ocorre a perda da consciência quase que imediata, então se consegue ter um rápido aparecimento dos efeitos. Tem uma vantagem de serem fármacos baratos, quando comparados a outros fármacos que são utilizados para eutanásia. Os barbitúricos indicados são aqueles que tem curta e ultracurta ação. Os barbitúricos causam depressão do sistema nervoso central, causando uma depressão central gradativa que vai se iniciar no córtex até atingir o centro cardiorrespiratório bulbar. Alguns exemplos são: Tiopental, Pentobarbital.

\section{Cetamina}

É um agente dissociativo, injetável, vai induzir rápida alteração da consciência, sendo administrada para que se consiga minimizar o sofrimento do animal, facilitando a contenção e/ou fornecer ambiente mais tranquilo para o próprio proprietário. As vantagens da Cetamina são: apresenta pronta disponibilidade, tem uma excelente capacidade de associar com outros fármacos e além de ser usada na via intravenosa, pode também usar na via intramuscular (Marchitelli \& Shearer, 2020). É um fármaco que não pode ser utilizado sozinho, por causa do seu efeito dissociativo, por isso não pode ser considerado um anestésico geral. A Cetamina é muito associada a fármacos que são miorrelaxantes de ação central, como por exemplo o Cloridrato de Xilazina (CFMV, 2012; CONCEA, 2018).

\section{Cloreto de potássio (KCL)}

De acordo com o Guia de Boas Práticas para Eutanásia em Animais (CFMV, 2012), só pode ser usado após o animal estar sob anestesia geral, sendo que sua aplicação só pode ser feita pela via intravenosa. É um ion cardiotóxico. Quando usando em animais conscientes, vai causar uma excitação das fibras nervosas do tipo C, e isso causa uma dor extrema, antes que esse animal venha a óbito. Quando feito após a anestesia geral, vai causar uma fibrilação ventricular cardíaca e a morte, em poucos minutos. Tem ação rápida e baixo custo. Porém, a desvantagem é que alguns relatos descrevem que quando feito de forma muito rápida, pode causar espasmos clônicos. Pode ser associado também com Cloreto ou Sulfato de Magnésio, injetado por via intravenosa ou intracardíaca, porém apenas em animais inconscientes ou sob anestesia geral (Marchitelli \& Shearer, 2020).

\section{Anestésicos inalatórios}

Gases ou vapores do anestésico que vão auxiliar no transporte do oxigênio, utilizados em elevadas concentrações e que vão levar o animal a uma hipóxia, causando a morte. Deve ser feita em câmaras próprias, para assegurar que quando as substâncias inalantes forem liberadas ocorra uma distribuição adequada, e que apenas o animal esteja exposto a esta alta concentração. É mais empregado em animais de pequeno porte, como por exemplos pássaros e roedores, porém também pode ser feita em cães e gatos. Neste método pode ser feita a eutanásia de vários animais juntos, é permitido. Deve-se levar em conta que os animais podem apresentar desconforto antes de perder a consciência. E também, tem que tomar cuidado com quem está realizando a eutanásia, pois estes acabam ficando um pouco expostos aos gases, que pode acarretar problemas de saúde, como por exemplo no fígado, pois alguns gases são hepatotóxicos (CFMV, 2012; CONCEA, 2018).

Os mais utilizados hoje em dia são o Halotano, Isoflurano e Sevoflurano, pois são facilmente administrados. Normalmente o sevoflurano é o de eleição, pois sabe-se que sua velocidade de indução é mais rápida, depois o isoflurano e por fim o halotano. Já o halotano tem o poder de promover uma perda da consciência mais rápida (CFMV, 2012; CONCEA, 2018).

\section{Comportamento do animal}

Oliveira et al. (2003) concluíram que os animais podem apresentar respostas comportamentais aos estímulos nocivos como: vocalização que pode ser um indicativo de angústia, ou até mesmo uma forma de fuga; expressões faciais e postura corporais que podem ser indicativas de dor; e salivação que pode indicar dor e ansiedade. Podem ocorrer também, esvaziamento da bexiga e relaxamento do ânus; 
contrações musculares causadas por tremores, calafrios e espasmos musculares; taquicardia; midríase e sudorese. É importante estar atento porque estas reações podem estar presentes no animal consciente e inconsciente

\section{Confirmação da morte}

De acordo com o Conselho Nacional de Controle de Experimentação Animal (CONCEA, 2018), para confirmarmos a morte do animal é necessário analisar alguns parâmetros, porque alguns animais aparentam estar inconscientes parecendo estar mortos, mas podem se recuperar um tempo depois, o que se torna inaceitável no momento da eutanásia.

Assim, deve-se observar os sinais a seguir: o animal deve estar em apneia, que é quando se tem ausência dos sinais respiratórios, tem que ter assistolia, que é o termo usado para quando se tem ausência dos batimentos cardíacos, confirmando isto através do uso de estetoscópio, ou até mesmo aparelhos como doppler ou ultrassom. Deve-se também estar atento a perda de reflexo corneal, que vai ser avaliado pela compressão digital da córnea, além de também ter que observar a perda da pulsação e mucosas pálidas que vão ocorrer pela ausência do fluxo sanguíneo. Vai ocorrer a perda do brilho e umidade das córneas e por fim o rigor mortis. É importante ressaltar que o descarte dos animais, devem seguir as normas na Agência Nacional de Vigilância Sanitária (ANVISA).

\section{Aceitabilidade da eutanásia}

Manzano et al. (2007) realizaram um estudo onde concluiu que a questão ética sobre a eutanásia deve ser mais debatida em cursos que lidam com animais. Médicos Veterinários devem sempre buscar serem mais humanos no ato da eutanásia, tendo responsabilidade de proteger a vida deste animal quando esta não representar uma ameaça à toda vida do planeta. Já Rollin (2003) em seu estudo sobre o assunto, mostrou que a maioria dos veterinários na cidade de Oshawa, no Canadá, não ficam satisfeitos quando utilizam a eutanásia para realizar controle populacional, pois acabam morrendo milhares de animais saudáveis. Os veterinários buscaram soluções como incentivo à doação de animais como forma de reduzir esta prática. Este estudo demonstrou que a eutanásia é mais aceita a partir do momento em que é feita em pacientes incuráveis. Já um estudo realizado por Christiansen et al. (2015) em que obteve a opinião dos proprietários, revelou que os veterinários são grandes influenciadores quando se deve tomar uma decisão relacionada a eutanásia. Então, o bom profissional é aquele que exerce sua influência a ponto de "facilitar" a escolha da eutanásia em situações que esta for indicada, apenas pela confiança que ele passa ao proprietário.

\section{Situações em que a eutanásia pode ser indicada}

Figueiredo \& Araújo (2001), consideraram que a questão legal da eutanásia, onde se recomenda que somente os médicos veterinários realizem este procedimento, após o consentimento, por escrito, do proprietário do animal, e o procedimento deve ser pautado na legislação vigente, fornecendo um amparo legal para os profissionais.

Rivera et al. (2006) citaram algumas situações em que pode ser necessária a eutanásia, como: doenças terminais, animais que possuem doenças zoonóticas, como a raiva, animais que foram vítimas de acidentes, seja ele de trânsito ou outros tipos, e que mesmo com a realização de cirurgia ou cuidados paliativos, o animal não teria uma qualidade de vida. Piirainen \& Taponen (2003) incluíram como principais causas de eutanásia a idade avançada do animal, problemas comportamentais, como a agressividade, neoplasias e doenças musculo esqueléticas. Johannes et al. (2007) em seu estudo informou que gatos com hemangiosarcoma visceral foram submetidos a eutanásia, pois é uma doença de prognóstico desfavorável.

Existem situações em que o médico veterinário é chamado para realizar a eutanásia por interesse do proprietário do animal, que na maioria das vezes eles alegam que é por questões financeiras, comportamento do animal e até mesmo a possibilidade de abandono (Spinosa \& Spinosa, 2006). Porém, Rivera et. al. (2006) citam que estas situações são um grande problema que sofrem pressão da opinião pública. 


\section{Eutanásia na clínica de pequenos animais}

Heiblum \& Tajeda (2007) afirmaram que os animais de companhia têm exercido um papel super importante, e isso tem se expandido. Hoje em dia o animal de estimação é visto como um membro da família, onde presta um apoio emocional e social. E tem casos que o cão é um prestador de serviço, como por exemplo para pessoas que são portadoras de necessidades especiais, logo sua morte pode ser extremamente dolorosa. É nesse momento em que o médico veterinário tem um papel importante, principalmente em situações críticas ou terminais, sempre informando sobre as opções de tratamento, caso haja uma, ou até mesmo sobre a prática da eutanásia. Se o proprietário decidir pela eutanásia é importante que se considere alguns aspectos como: quando será realizado o procedimento, onde será realizado, se terá algum membro da família presente. É importante que o médico veterinário também consiga dar um apoio e converse com o proprietário para que não haja nenhum sentimento de culpa em ter escolhido a eutanásia, uma vez que dependendo da doença se torna a melhor opção.

Então, de acordo com Schmidt \& Booker (1982), 3 circunstâncias e cenários devem ser levados em conta quando for realizar a eutanásia dos animais: $1^{\circ}$ é aquela relacionada com o cenário clínico, em que o proprietário deve decidir pela eutanásia e o momento que irá realizar, já a $2^{\circ}$ está relacionada as pessoas que estão envolvidas em eutanásias coletivas, como por exemplo, para controle de animais de rua, e a $3^{\circ}$ é aquela relacionada ás pessoas que trabalham com a eutanásia durante a realização de pesquisas científicas.

\section{Finalização humanitária (Human endpoint) em animais de laboratório}

Lapchik et al. (2009) citaram que os animais são utilizados em ensino e pesquisa há centenas de anos. A utilização de animais em laboratório, tanto para fins médicos como para fins comerciais, é sempre uma questão que envolve polêmica. São utilizados animais de várias espécies, principalmente os camundongos. Os animais são utilizados em experiências científicas e em testes, para comprovar a eficácia de vacinas, medicamentos, estudos de imunologia, doenças infecciosas, parasitárias, neoplasias dentre outras. Devido a isso, a utilização de animais no ensino e pesquisa é regida e apoiada por diretrizes e códigos de conduta ética e moral, para determinar o que é e o que não é aceitável.

De acordo com Russell \& Burch (1959), os 3R's significam replacement (substituição), reduction (redução) e refinement (refinamento), são princípios preconizados para serem utilizados no ensino e na pesquisa. Substituição significa utilizar materiais que não tenham sensibilidade no lugar de animais vivos, como por exemplo cultura de tecidos, modelos 3D ou modelos em computador. A redução tem como objetivo diminuir o número de animais que é utilizado para que se consiga obter informações e resultados significativos e o refinamento visa reduzir as técnicas que são invasivas ou até mesmo desumanas no manejo dos animais. Essas diretrizes são utilizadas para que se consiga diminuir o número de animais e aprimorar os métodos que estão sendo utilizados para realização de procedimentos experimentais.

De acordo com Dias \& Lapchik (2017), a finalização humanitária é sempre o ponto mais extremo de todo procedimentos e estudos. Por isso, faz-se extremamente necessário que todo experimento ou estudo tenha um ponto de intervenção definido, onde se consiga coletar dado científicos de qualidade e que ao mesmo tempo evite o sofrimento do animal (Richmond, 1999). Este é o ponto em que a dor ou o distress do animal em experimentação será aliviado ou interrompido, sendo extremamente necessário em estudos que causam dor extrema, sofrimento grave, morte, em animais que estão infectados, como câncer e doenças infecciosas e parasitárias.

Morton (2005) descreveu que todo pesquisador deve especificar qual é o resultado que ele quer alcançar, e a partir do momento em que o animal não estiver mais apresentando informações úteis, por causa de problemas fisiológicos e psicológicos causado pelo experimento, deve-se realizar o ponto final. A legislação brasileira para uso de animais em ensino e pesquisa exige que todo projeto de pesquisa deve conter as descrições de pontos-finais apropriados para a espécie animal e procedimentos em uso. Em protocolos que envolvem morte como desfecho provável, a escolha de um ponto-final humanitário adequado é ainda mais importante (CONCEA, 2015).

Para definir os pontos finais humanitários de um experimento devemos avaliar as condições clínicas e comportamentais dos animais que estão em experimentação, observando os seguintes aspectos: a 
aparência física; peso; temperatura corporal; estado do pelo; função fisiológica como a alteração na frequência respiratória, observando se tem a presença de diarreia e/ou diarreia com sangue; observar o comportamento dos animais quando manuseados, se eles estão se mostrando agressivos ou apresentam comportamento normal. É importante observar o animal se locomovendo dentro da caixa, observando marcha e postura. Para quantificar os parâmetros acima utilizamos uma tabela de pontuação de score clínico (Tabela 1). O animal deve ser observado diariamente e caso sua pontuação atinja 3, deve-se passar a observar esse animal duas vezes ao dia, e se a pontuação atingir 6 já devemos realizar a eutanásia. É importante ressaltar que, animais moribundos ou estado comatoso já estão em processo de morte, ou seja, estão além da consciência do sofrimento, logo devemos realizar a finalização humanitária antes que o animal atinja estes estágios, para evitar a dor e o sofrimento (Dias \& Lapchik, 2017).

Tabela 1. Score Corporal de intervenção e pontos finais em animais de laboratório segundo o IACUC (2011)

\begin{tabular}{|l|l|l|l|l|}
\hline N. ${ }^{\circ}$ do animal & & & & \\
\hline Data & $01 / 06$ & $02 / 06$ & $03 / 06$ & $04 / 06$ \\
\hline Aspeto & & & & \\
\hline Peso corporal & & & & \\
\hline Estado do pelo & & & & \\
\hline $\begin{array}{l}\text { Alteração da } \\
\text { temperatura } \\
\text { corporal }\end{array}$ & & & & \\
\hline $\begin{array}{l}\text { Função } \\
\text { fisiológica }\end{array}$ & & & & \\
\hline $\begin{array}{l}\text { Dispneia e/ou } \\
\text { taquipneia }\end{array}$ & & & & \\
\hline $\begin{array}{l}\text { Ingestão de } \\
\text { alimentos }\end{array}$ & & & & \\
\hline Ambiente & & & & \\
\hline $\begin{array}{l}\text { Fezes moles ou } \\
\text { diarreia }\end{array}$ & & & & \\
\hline $\begin{array}{l}\text { Diarreia com } \\
\text { sangue }\end{array}$ & & & & \\
\hline Comportamentos & & & & \\
\hline Manuseamento & & & & \\
\hline Agressão & & & & \\
\hline Locomoção & & & & \\
\hline Marcha anormal & & & & \\
\hline Postura anormal & & & & \\
\hline $\begin{array}{l}\text { Relutância em } \\
\text { mover-se }\end{array}$ & & & & \\
\hline Indicadores específicos dos procedimentos \\
\hline \\
observações & & & & \\
\hline Pontuação total & & & & \\
\hline Açossas & & & \\
\hline
\end{tabular}

\begin{tabular}{|c|c|}
\hline Aspeto & Pontuação \\
\hline \multicolumn{2}{|l|}{ Peso corporal } \\
\hline $5-10 \%$ de perda de peso & 1 \\
\hline $11-15 \%$ de perda de peso & 2 \\
\hline $16-20 \%$ de perda de peso & 3 \\
\hline $20 \%+$ de perda de peso & EUTANÁSIA \\
\hline \multicolumn{2}{|l|}{ Estado do pelo } \\
\hline Ligeira piloereção| & 2 \\
\hline Pilo ereção notória & 3 \\
\hline \multicolumn{2}{|l|}{$\begin{array}{l}\text { Alteração de temperatura corporal } \\
\text { Faixa normal: } 36,5^{\circ} \mathrm{C}\left(35,2^{\circ} \mathrm{C}-37,9^{\circ} \mathrm{C}\right)\end{array}$} \\
\hline Até $2^{\circ} \mathrm{C}$ acima da faixa normal & 1 \\
\hline Até $3^{\circ} \mathrm{C}$ acima da faixa normal & 2 \\
\hline$>3^{\circ} \mathrm{da}$ faixa normal & EUTANÁSIA \\
\hline Hipotermia $<35,2^{\circ} \mathrm{C}$ & EUTANÁSIA \\
\hline \multicolumn{2}{|l|}{ Função fisiológica } \\
\hline Taquipneia (respiração acelerada) & 1 \\
\hline Dispneia (dificuldade em respirar) & 3 \\
\hline \multicolumn{2}{|l|}{ Ambiente } \\
\hline Fezes moles ou diarreia & 1 \\
\hline Diarreia com sangue & EUTANÁSIA \\
\hline \multicolumn{2}{|l|}{ Comportamento } \\
\hline $\begin{array}{l}\text { Tenso e nervoso durante } \\
\text { manuseamento }\end{array}$ & 1 \\
\hline $\begin{array}{l}\text { Em notório sofrimento durante o } \\
\text { manuseamento, p. ex. tremores, } \\
\text { vocalizações, agressividade }\end{array}$ & 3 \\
\hline \multicolumn{2}{|l|}{ Locomoção } \\
\hline Marcha/postura ligeiramente anormal & 1 \\
\hline $\begin{array}{l}\text { Marcha/postura significativamente } \\
\text { anormal }\end{array}$ & 2 \\
\hline $\begin{array}{l}\text { Problemas de mobilidade } \\
\text { significativos/relutância em mover-se }\end{array}$ & 3 \\
\hline Imobilidade $>24 \mathrm{~h}$ & EUTANÁSIA \\
\hline \multicolumn{2}{|c|}{ Indicadores específicos de procedimentos } \\
\hline Convulsão & EUTANÁSIA \\
\hline & \\
\hline
\end{tabular}

\begin{tabular}{|c|c|}
\hline \multicolumn{2}{|l|}{ Ações } \\
\hline $\begin{array}{c}\text { Pontuação } \\
\text { total }\end{array}$ & \\
\hline 3 & $\begin{array}{l}\text { Aumentar a frequência do acompanhamento } \\
\text { para 2x ao dia }\end{array}$ \\
\hline 6 & Implementar limite critico humano (Eutanásia) \\
\hline
\end{tabular}


É importante destacar que, para o ponto final humanitário ser aplicado corretamente é de extrema importância que haja responsabilidade, treinamento, dedicação, comprometimento e vontade de todos os membros da equipe que estão realizando o procedimento experimental.

De acordo com o CONCEA (2018) e Marchitelli \& Shearer (2020), para realização da eutanásia em roedores (ratos, camundongos, hamnsters e cobaias) são utilizados como métodos aceitáveis: os barbitúricos intravenosos ou intraperiotoneal, porém estes devem estar associados com anestésico local, como por exemplo lidocaína a 2\%; anestésicos gerais intravenosos, como o propofol e a associação de cetamina com xilazina; e anestésicos inalatórios (halotano, isoflurano ou sevoflurano). Em coelhos, utilizamos barbitúricos, anestésicos gerais como propofol ou embutramina. A anestesia inalatória também pode ser feita, porém caso seja necessário, podemos realizar outros métodos para confirmar a eutanásia. $\mathrm{O}$ indicado é utilizar a sobre dose de pelo menos 3 vezes da dose da anestesia geral.

Há anos o $\mathrm{CO}_{2}$ era o método mais indicado para eutanásia em roedores, porém mesmo este tendo um potencial anestésico e analgésico, após alguns anos de pesquisa foi comprovado que esse não é um método humanitário. $\mathrm{O} \mathrm{CO}_{2}$ tem alto risco de comprometer o bem-estar dos animais, em médias concentrações (acima de 40\%), ocorre a formação de ácido carbônico nas mucosas, causando dor e sofrimento. E em altas concentrações (acima de 80\%), causa lesões no trato respiratório, pulmões, estresse e sofrimento animal (CONCEA, 2018).

Um método muito utilizado e aceito para eutanásia em roedores é o uso de isoflurano embebido em uma gaze ou algodão, que deve colocado em uma caixa fechada junto com o animal, é indicado que esta caixa seja transparente para que se consiga visualizar o momento do óbito. Em camundongos é muito utilizada quando se quer realizar a finalização de vários animais. É indicado que haja uma distância entre o algodão ou gaze do animal, porque o odor do anestésico pode causar irritação das mucosas (CONCEA, 2018).

Antes do descarte do animal, a morte deve ser confirmada pelo médico veterinário responsável, então deve-se observar alguns parâmetros, como: cianose; alteração na cor da pupila; ausência de reflexo palpebral, corneal e interdigital; ausência de pulso e de movimentos respiratórios e cardíacos (devem ser analisados utilizando um estetoscópio); palidez das membranas mucosas e rigor mortis. Apenas o rigor mortis, confirma a morte do animal sozinho (Dias \& Lapchik, 2017).

Para que o ponto final humanitário seja aplicado corretamente é de extrema importância que haja responsabilidade, treinamento, dedicação, comprometimento e vontade de todos os membros da equipe que estão realizando o procedimento experimental.

\section{Impactos psicológicos no médico veterinário}

Existem várias teorias sobre o sofrimento psíquico no trabalho, e que o trabalho também exerce influência sobre o estado emocional do indivíduo. Formighieri (2003) citou que os profissionais da saúde estão constantemente sendo expostos e afetados a situações estressantes, como: carga horária exaustiva; desvalorização da profissão; cobranças excessivas em querer salvar a vida do paciente; e cobrança pessoal de ter que sempre estar estudando e se especializando para acompanhar sua área de atuação. A Síndrome de Burnout, segundo Freudenberger (1974), é a síndrome que é caracterizada pela presença de uma exaustão emocional, despersonalização e falta de realização profissional. É uma das síndromes que vem sendo estudada em todo o mundo, e é um dos principais fatores de causa mortalidade, da perda da saúde mental, e perda do bem-estar dos profissionais que a desenvolvem. É uma síndrome que está mais relacionada com um problema social e do ambiente profissional, do que com o próprio indivíduo. A área da medicina veterinária é a mais vulnerável a esta enfermidade. Platt et. al. (2010), realizaram 28 estudos relacionados a Burnout que demonstraram que $67 \%$ dos médicos veterinários apresentaram sinais compatíveis com a Síndrome de Burnout.

Trigo et al. (2007) dizem que os sintomas mais característicos são: exaustão emocional, que também abrange desesperança, depressão, raiva, irritabilidade, tensão, perda de empatia, aumento da suscetibilidade para outras doenças porque o estresse leva a uma diminuição da imunidade, náuseas, tensão muscular, dor lombar, cervical e distúrbios do sono. Pode ocorrer também um distanciamento afetivo, em que o indivíduo tem uma sensação de alienação com os outros, sendo que na maioria das vezes a presença deste individuo se torna desagradável e não desejada. Neste caso é indicado que se 
procure um auxílio médico e psicológico urgente, e por muitas vezes é indicado que se afaste do local de trabalho por um tempo.

A Síndrome de Burnout já se encontra registrada no CID 10 (Classificação Estatística Internacional de Doenças e Problemas Relacionadas à Saúde) e é uma doença que as leis brasileiras já reconhecem como uma doença causada pelo trabalho (Batista et al., 2011). O Brasil, em uma pesquisa realizada pela International Stress Association, que foi publicada em 2003, assumiu a segunda posição sobre níveis de estresse, só perdendo para o Japão (Barhtolo, 2007).

Rabelo \& Sanches (2011) descreveram que os médicos veterinários não são devidamente reconhecidos pela sociedade como profissionais, os tornando menos importantes na área da saúde, assim como, a formação não tem o devido reconhecimento, ainda existe uma grande dificuldade de conseguir um ambiente mais técnico, mais apropriado, com uma estrutura boa para o trabalho, principalmente na área de clínica de pequenos. Os autores também descrevem que a má remuneração é um dos fatores. $\mathrm{O}$ afeto, cuidado e humanização dos animais de estimação vem aumentando no decorrer dos anos, e na maioria das vezes estes animais se tornam membros da família, e por causa disso a cobrança ao médico veterinário aumentou. Devido a todos estes fatores, os veterinários fazem parte do grupo de alto risco de suicídio, sendo cerca de duas vezes maior que de outros profissionais da saúde (Bartram \& Baldwin, 2008).

Os procedimentos que envolvem a morte, acabam acarretando no desgaste emocional, que acaba implicando em um comprometimento físico e psicológico no indivíduo (Brassioli, 2006). Schneider (1996) cita que os médicos veterinários são aqueles que tem uma grande importância na decisão da eutanásia, e assim como todos envolvidos neste ato, também são afetados pelos dilemas morais e emocionais. E isso acaba implicando em grandes efeitos psicológicos, principalmente em profissionais que trabalham na área da experimentação animal, que diariamente necessitam realizar eutanásia em muitos animais, sendo estes saudáveis ou não (Broom, 1986).

\section{Considerações finais}

Ressaltamos a importância de se elucidar sobre o procedimento de realização da eutanásia humanitária desde a graduação de medicina veterinária. Além disso, destacamos que o profissional médico veterinário deve sempre está informado sobre a legislação que rege a eutanásia do CONCEA e do CFMV, pois estas estão sempre sofrendo atualizações que devem ser seguidas na prática da eutanásia.

O método de escolha para a eutanásia sempre vai depender do objetivo e da causa que está sendo analisada, pois todas as técnicas possuem seus prós e contras, então o profissional deve ter conhecimento para escolher o método adequado para cada situação.

Deve-se considerar todo impacto psicológico que este ato causa nos proprietários dos animais e também no próprio médico veterinário, que pode estar apresentando muitos sinais da doença de Burnout e não consegue identificar por aquilo que está passando, deixando explicito que se deve procurar ajuda de um profissional no momento que se identificar o problema.

Uma das questões mais importantes é esclarecer que a eutanásia mesmo que ainda não seja aceita e não seja vista de uma forma positiva perante a sociedade, é que em muitos casos ela se faz de extrema importância, pois seu principal objetivo é acabar com o sofrimento oferecendo bem estar para o animal.

\section{Referências}

Barhtolo, W. R. (2007). Estresse pós-traumático. Revista de Psicologia: Saúde Mental e Segurança Pública, Belo Horizonte, 2(4).

Bartram, D. J., \& Baldwin, D. S. (2008). Veterinary surgeons and suicide: influences, opportunities and research directions. Veterinary Record, 162(2), 36-40. https://doi.org/10.1136/vr.162.2.36

Batista, J. B. V., Carlotto, M. S., Coutinho, A. S., \& Augusto, L. G. S. (2011). Síndrome de Burnout: confronto entre o conhecimento médico e a realidade das fichas médicas. Psicologia Em Estudo, 16(3), 429-435. https://doi.org/10.1590/S1413-73722011000300010

Botoni, L. S., Veado, J. C. C., \& Val, A. P. C. (2012). Distanásia ou eutanásia: quando você colocaria 
o ponto final? MEDVEP. Rev. Cient. Med. Vet., 108-111.

Brassioli, S. R. A. (2006). Sofrimento psíquico no trabalho: ensaio de reflexão sobre sentimentos de trabalhadores em relação à eutanásia animal. Dissertação (mestrado) - Universidade de São Paulo Faculdade de Saúde Pública, São Paulo.

Broom, D. M. (1986). Indicators of poor welfare. British Veterinary Journal, 142(6), 524-526.

CFMV. (2012). Resolução N 1.000 de 11 de maio de 2012. Conselho Federal de Medicina Veterinária - Dispõe Sobre Procedimentos e Métodos de Eutanásia Em Animais e Dá Outras Providências., 124-125.

CFMV. (2016). Aprova o Código de ética do Médico Veterinário. Conselho Federal de Medicina Veterinária - Resolução $N^{\circ} 1138$ de Dezembro de 2016., 162-164.

Christiansen, S. B., Kristensen, A. T., Lassen, J., \& Sandøe, P. (2015). Veterinarians' role in clients' decision-making regarding seriously ill companion animal patients. Acta Veterinaria Scandinavica, 58(1), 30. https://doi.org/10.1186/s13028-016-0211-x

CONCEA. (2015). Introdução Geral" do Guia Brasileiro de Produção, Manutenção ou Utilização de Animais para Atividades de Ensino ou Pesquisa Científica". Controle Nacional de Controle de Experimentação Animal-CONCEA, 1-33.

CONCEA. (2018). Diretriz da Prática de Eutanásia do CONCEA.”. Controle Nacional de Controle de Experimentação Animal, 1-49.

Dias, H. L. M., \& Lapchik, V. B. V. (2017). Finalização humanitária. In Lapchik VBV, Mattaraia VGM, Ko GM. Cuidados e manejo de animais de laboratório. São Paulo: Atheneu (pp. 603-615).

Figueiredo, A. C. C., \& Araújo, F. A. A. (2001). Eutanásia animal em centros de controle de zoonoses. Revista Do Conselho Federal de Medicina Veterinária, 23, 12-17.

Formighieri, V. J. (2003). Burnout em fisioterapeutas: influência sobre a atividade de trabalho e bemestar físico e psicológico [Dissertação (mestrado) - Universidade Federal de Santa Catarina, Centro Tecnológico.]. http://repositorio.ufsc.br/xmlui/handle/123456789/84557

Freudenberger, H. (1974). Staff Burnout. Journal of Social Issues, 30(1),159- 165. Disponível em: https://doi.org/10.1111/j.1540-4560.1974.tb00706.x

Heiblum, F. M., \& Tajeda, P. A. (2007). A Eutanásia e Tanatologia em pequenos animais. Jornal de Veterinária: Comportamento Clínico, Aplicações e Investigação, 2(2), 35-39.

IACUC. (2011). Guideline Humane Intervention and Endpoints for Laboratory Animal Species (p. 7). http://www.inia.es/GCONTREC/PUB/iacucguideline-humaneendpoints-8_23_11_1431426542912.pdf

Johannes, C. M., Henry, C. J., Turnquist, S. E., Hamilton, T. A., Smith, A. N., Chun, R., \& Tyler, J. W. (2007). Hemangiosarcoma en gatos: 53 casos (1992-2002). Jornal Da Associação Americana de Medicina Veterinária, 231(12), 1851-1856.

Lapchik, V. B. V., Mattaraia, V. G. M., \& Ko, G. M. (2009). Cuidados e manejo de animais de laboratório. In Cuidados e Manejo de Animais de Laboratório (p. 708).

Manica, J. (2018). Anestesiologia: princípios e técnicas (Artmed (ed.); 4th ed.).

Manzano, M. A., Pachaly, J. R., Majczak, K. H., Silva, A. V., \& Ciffoni, E. M. G. (2007). A eutanásia animal na visão de estudantes de Medicina Veterinária e Ciências Biológicas. Revista Brasileira de Ciência Veterinária, 14(3).

Marchitelli, B., \& Shearer, T. (2020). Small Animal Euthanasia,An Issue of Veterinary Clinics of North America: Small Animal Practice, E-Book. Elsevier Health Sciences. https://books.google.com.br/books?id=5NjaDwAAQBAJ

Morton, D. (2005). Guía para el punto final humanitario en la experimentación animal para la investigación biomédica: Aspectos éticos, legales y prácticos. Laboratory Animals, 8, 5-12.

Oliveira, H. P., Alves, G. E. S., \& Rezende, C. M. de F. (2003). Eutanásia em medicina veterinária. Escola de Veterinária, 1, 1-14.

Piirainen, H. P., \& Taponen, S. (2003). Problemas Comportamentais com Motivo de Eutanásia. Super Decorrente, 109(3), 132-138. 
Platt, B., Hawton, K., Simkin, S. \& Mellanby, R.J. (2010). Systematic review of the prevalence of suicide in veterinary surgeons. Occupational Medicine, 60(6),436-446. Disponível em: https://doi.org/10.1093/occmed/kqq044

Rabelo, R. C., \& Sanches, J. F. (2011). A Síndrome Bornout em Medicina Veterinária. Journal LAVECC, 3(4), 286-300.

Richmond, J. (1999). Criteria for humane endpoints. Humane Endpoints in Animal Experiments for Biomedical Research: Proceedings of the International Conference, 1999, 26-32.

Rivera, E. A. B.; Amaral, M. H. \& Nascimento, V. P. (2006). Ética e Bioética aplicadas à Medicina Veterinária. Goiânia, p.267-298.

Rollin, B. E. (2003). An ethicist's commentary on veterinarians treating unowned animals and euthanizing unwanted animals. The Canadian Veterinary Journal $=L a$ Revue Veterinaire Canadienne, 44(5), 363-364. http://www.ncbi.nlm.nih.gov/pubmed/12757128

Russell, W. M. S., \& Burch, R. L. (1959). The principles of humane experimental technique. Methuen. https://caat.jhsph.edu/principles/chap4d

Schmidt, R. E., \& Booker, J. L. (1982). Effects of different surgical stresses on hematologic and blood chemistry values in dogs. Journal American Animal Hospital Association, 18(5), 758-762.

Schneider, B. J. (1996). Euthanasia and the veterinarian. The Canadian Veterinary Journal $=$ La Revue Veterinaire Canadienne, 37(4), 217-218. http://www.ncbi.nlm.nih.gov/pubmed/8801015

Spinosa, H. S. \& Spinosa, F. R. N. (2006). Eutanásia. In: Spinosa, H. S.; Górniak, S. L.; Bernardi, M. M. Farmacologia Aplicada à Medicina Veterinária. Rio de Janeiro: Guanabara koogan, $4^{\mathrm{a}}$ edição, p. $790-794$.

Trigo, T. R., Teng, C. T., \& Hallak, J. E. C. (2007). Síndrome de burnout ou estafa profissional e os transtornos psiquiátricos. Archives of Clinical Psychiatry (São Paulo), 34(5), 223-233. https://doi.org/10.1590/S0101-60832007000500004

Histórico do artigo:

Recebido: 8 de outubro de 2020.

Aprovado: 28 de outubro de 2020.

Disponível online: 5 de janeiro de 2020
Licenciamento: Este artigo é publicado na modalidade Acesso Aberto sob a licença Creative Commons Atribuição 4.0 (CC-BY 4.0), a qual permite uso irrestrito, distribuição, reprodução em qualquer meio, desde que o autor e a fonte sejam devidamente creditados. 